\title{
ASO Visual Abstract: Effect of the Ductal Carcinoma In Situ Margin Consensus Guideline Implementation on Reexcision Rates, Satisfaction, and Cost
}

\section{Neal Bhutiani, MD, $\mathrm{PhD}^{\mathbf{1}}$, Michelle M. Holland, BS ${ }^{1}$, Megan K. Mercer, MD ${ }^{\mathbf{1}}$, Marilyn Donaldson, $\mathbf{R N}^{\mathbf{1}}$, Tiffany S. Berry, MD, FACS ${ }^{2}$, Kelly M. McMasters, MD, PhD, FACS ${ }^{1}$, and Nicolás Ajkay, MD, FACS ${ }^{1}$ \\ ${ }^{1}$ Department of Surgery, Division of Surgical Oncology, University of Louisville, Louisville, KY ; ${ }^{2}$ Department of Surgery, Division of Breast Surgery, Norton Hospital, Louisville, KY}

The 2016 consensus guideline on margins for breastconserving surgery with whole-breast irradiation for ductal carcinoma in situ sought to decrease breast tumor recurrence. However, its implementation resulted in an increase in reexcisions and mastectomy conversions at two institutions (https://doi.org/10.1245/s10434-021-10120-z).
Publisher's Note Springer Nature remains neutral with regard to jurisdictional claims in published maps and institutional affiliations.

\section{Outcomes After DCIS Margin Consensus Guideline Implementation}

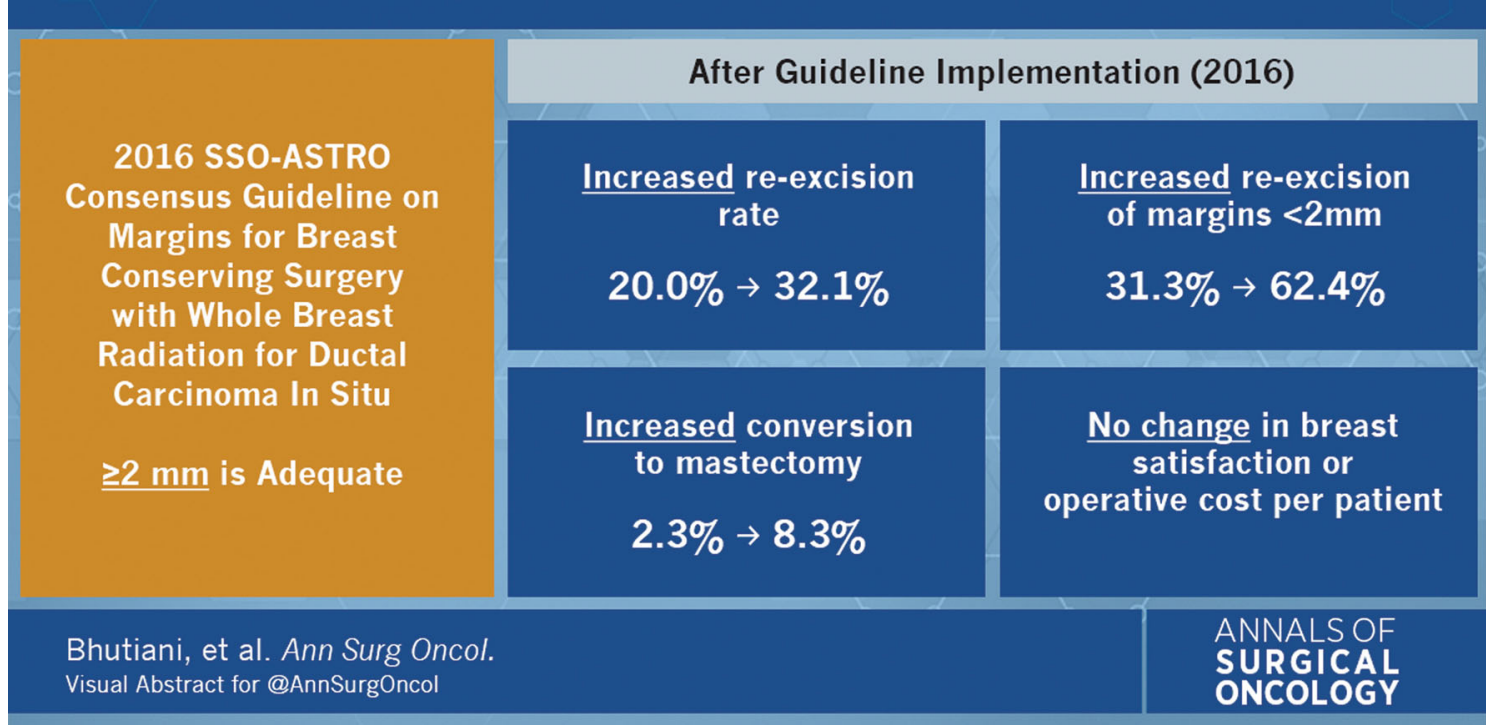

(C) Society of Surgical Oncology 2021

Published Online: 14 June 2021

N. Ajkay, MD, FACS

e-mail: Nicolas.ajkay@louisville.edu 